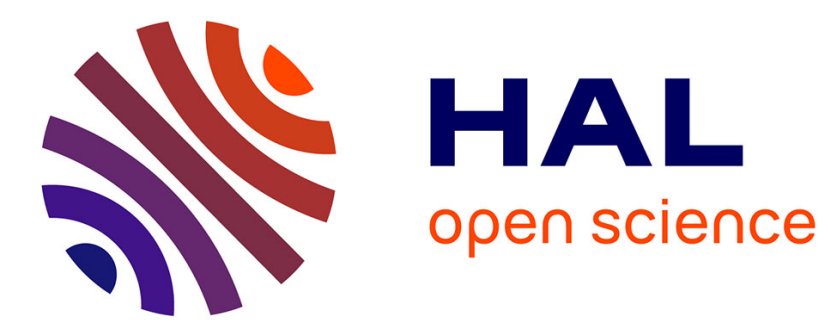

\title{
Magnitude of isotope/temperature scaling for interpretation of central Antarctic ice cores
}

J. Jouzel, F. Vimeux, N. Caillon, G. Delaygue, G. Hoffmann, V. Masson-Delmotte, F. Parrenin

\section{- To cite this version:}

J. Jouzel, F. Vimeux, N. Caillon, G. Delaygue, G. Hoffmann, et al.. Magnitude of isotope/temperature scaling for interpretation of central Antarctic ice cores. Journal of Geophysical Research, 2003, 108 (D12), 10.1029/2002JD002677 . hal-03101222

\section{HAL Id: hal-03101222 \\ https://hal.science/hal-03101222}

Submitted on 28 Jan 2021

HAL is a multi-disciplinary open access archive for the deposit and dissemination of scientific research documents, whether they are published or not. The documents may come from teaching and research institutions in France or abroad, or from public or private research centers.
L'archive ouverte pluridisciplinaire HAL, est destinée au dépôt et à la diffusion de documents scientifiques de niveau recherche, publiés ou non, émanant des établissements d'enseignement et de recherche français ou étrangers, des laboratoires publics ou privés. 


\title{
Magnitude of isotope/temperature scaling for interpretation of central Antarctic ice cores
}

\author{
J. Jouzel, ${ }^{1}$ F. Vimeux, ${ }^{1,2}$ N. Caillon, ${ }^{1,3}$ G. Delaygue, ${ }^{1,4}$ G. Hoffmann, ${ }^{1}$ \\ V. Masson-Delmotte, ${ }^{1}$ and F. Parrenin ${ }^{1,5,6}$ \\ Received 20 June 2002; revised 12 November 2002; accepted 10 January 2003; published 24 June 2003.
}

[1] The conventional interpretation of ice core deuterium and oxygen 18 isotope profiles based on the use of present-day observations (spatial slope) underestimates glacialinterglacial surface temperature changes in Central Greenland by up to a factor of two. This likely results from changes in the seasonality of the precipitation due to the particular location of the Greenland ice sheet next to the highly variable northern polar front. In this regard the situation is much simpler for central Antarctica and this should be reflected in the temperature interpretation of ice core isotopic records. With this in mind, we closely examine all relevant information, focusing on the East Antarctic Plateau where both model and empirical isotope-temperature estimates are available. We point to the fact that correctly accounting for the influence of ocean isotopic change is important when interpreting deuterium profiles from ice cores in this region. The evidence presently available indicates that, unlike for Greenland, the present-day spatial-slope can probably be taken as a surrogate of the temporal slope to interpret glacial-interglacial isotopic changes at sites such as Vostok and EPICA Dome C. Corresponding temperature changes are within $-10 \%$ to $+30 \%$ of those obtained from the conventional interpretation based on the use of the spatial slope. INDEX TERMS: 1040 Geochemistry: Isotopic composition/ chemistry; 1827 Hydrology: Glaciology (1863); 3344 Meteorology and Atmospheric Dynamics:

Paleoclimatology; 9310 Information Related to Geographic Region: Antarctica; KEYWORDS: water isotopes, temperature estimate, Antarctica, deuterium, oxygen 18

Citation: Jouzel, J., F. Vimeux, N. Caillon, G. Delaygue, G. Hoffmann, V. Masson-Delmotte, and F. Parrenin, Magnitude of isotope/ temperature scaling for interpretation of central Antarctic ice cores, J. Geophys. Res., 108(D12), 4361, doi:10.1029/2002JD002677, 2003.

\section{Introduction}

[2] Past temperature estimates from polar ice cores have long been limited to the interpretation of the isotopic composition of the ice in $\mathrm{HDO}$ or $\mathrm{H}_{2}{ }^{18} \mathrm{O}$ (expressed as $\delta \mathrm{D}$ or $\delta^{18} \mathrm{O}$ with respect to the Standard Mean Ocean Water, SMOW). This method is based on the existence of a linear relationship between the mean annual values of the presentday isotopic content of the precipitating snow $\delta \mathrm{p}(\delta$ stands either for $\delta \mathrm{D}$ or $\delta^{18} \mathrm{O}$ ) and of the temperature of the site, particularly well obeyed over Antarctica [Lorius and Merlivat, 1977] and Greenland [Johnsen et al., 1989]. It also

${ }^{1}$ IPSL/Laboratoire des Sciences du Climat et de 1'Environnement, Gif sur Yvette, France.

${ }^{2}$ Institut de Recherche pour le Développement, Paris, France. USA.

${ }^{3}$ Now at Scripps Institution of Oceanography, La Jolla, California,

${ }^{4}$ Centre d'Enseignement et de Recherche en Géosciences de l'Environnement, Aix en Provence, France.

${ }^{5}$ Laboratoire de Glaciologie et Géophysique de l'Environnement, CNRS, Saint Martin d'Hères, France.

${ }^{6}$ Now at Laboratoire d'Etudes en Geophysique et Oceanographie Spatiales, OMP, Toulouse, France.

Copyright 2003 by the American Geophysical Union. 0148-0227/03/2002JD002677 relies on a variety of isotopic models which provide a theoretical basis for this observation (Dansgaard [1964], Jouzel et al. [2000], and Hoffmann et al. [2000] for recent reviews). Recently, this method has been challenged by two other approaches. First, borehole paleothermometry uses the inverse modeling of heat diffusion from the surface into the ice, enabling estimates of recent and long-term temperature changes (glacial-interglacial timescale). Second, the isotopic composition of the air is slightly modified during firnification by physical processes such as gravitation and thermal diffusion, and this property can be exploited, in particular in the case of rapid changes which cause a detectable anomaly in the isotopic composition of nitrogen and argon [Jouzel, 1999, and references therein].

[3] Those two methods have now been extensively applied to deep ice cores from central Greenland for which they are particularly well suited. First, at these sites accumulation is relatively high which limits the smoothing by diffusive heat flow and allows access to the temperature conditions prevailing at the Last Glacial Maximum (LGM) 20 kyr BP (thousands of years before present) both at GRIP [Johnsen et al., 1995; Dahl-Jensen et al., 1998] and GISP2 [Cuffey et al., 1995]. Second, central Greenland experienced large and rapid climatic fluctuations during the last glacial, typically $10^{\circ} \mathrm{C}$ or more in one hundred years or less, and the 


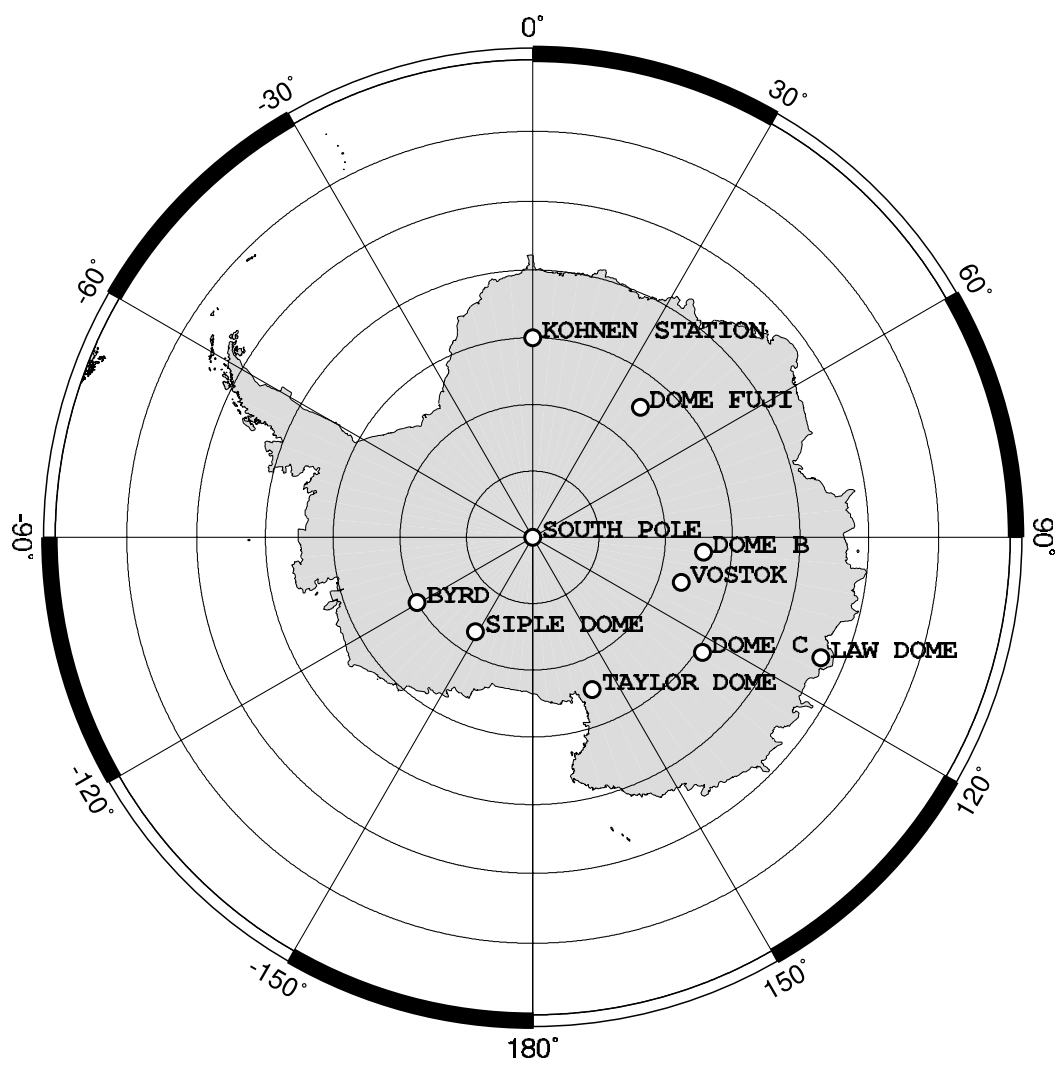

Figure 1. Influence of the change in the deuterium content of seawater in Antarctica. This map shows the difference in the deuterium content of the precipitation between two experiments performed with the NASA/GISS isotopic GCM for a modern climate [Delaygue, 2000]; one with $\delta \mathrm{D}=4 \%$ (modern conditions) and the other with $\delta \mathrm{D}=13.6 \%$ (glacial composition). Also reported on this map are the main drilling sites in Antarctica.

resulting isotopic anomalies can thus be well documented [Severinghaus et al., 1998]. These two complementary approaches allow temperature to be estimated at certain times in the past, and provide a way to calibrate the continuous record that can be inferred from the isotopic composition of the ice. This calibration clearly demonstrates that the slope observed between the present-day mean values of the isotopic composition of the snow and of the surface temperature at the site, $\mathrm{T}_{\mathrm{s}}$, cannot be used to interpret quantitatively Greenland isotopic records (hereafter the spatial slope, $\mathrm{S}_{\text {spat }}$, generally defined at a large regional scale using at each site isotopic values averaged over a few years and $10 \mathrm{~m}$ deep temperatures). In other words, the spatial slope and the temporal slope, $\mathrm{S}_{\text {temp }}$ (the relationship describing the variation of isotopic concentrations with temperature through different climates over time, at a single geographic location) are not similar. Hereafter, the ratio of the spatial to the temporal slope is denoted as $\mathrm{R}_{\text {slopes }}=\mathrm{S}_{\text {spat }} / \mathrm{S}_{\text {temp }}$, e.g., when $\mathrm{R}_{\text {slopes }}>1$ the true temperature change is larger by a factor $R_{\text {slopes }}$ than the one, $\Delta \mathrm{T}_{\mathrm{s} \text { (spat) }}$, estimated by the conventional approach, and vice versa ( $\Delta$ denoting the difference between two different periods). Indeed, all of the studies mentioned above (borehole paleothermometry and isotopic anomalies) unambiguously show that using the spatial slope as a surrogate for the temporal slope, a method referred to as the "isotopic paleothermometer," underestimates Greenland temperature changes by up to a factor of 2 [Jouzel, 1999, and references therein].

[4] In Antarctica (Figure 1), both paleothermometry and the use of nitrogen and argon isotopes pose some problems. First, the low accumulation that prevails at East Antarctic inland sites such as Vostok erases the glacial-interglacial surface temperature signal at the depth of the Last Glacial Maximum (LGM). This prevents accurate estimation of the glacial-interglacial temperature change by borehole paleothermometry at Vostok [Rommelaere, 1997]. In fact, to be applied this method requires additional assumptions [Salamatin et al., 1998]. Second, unlike central Greenland, central Antarctica did not experience abrupt temperature changes, and gas isotopic anomalies due to thermal diffusion are, in principle, difficult to detect. Thus, there is no perfect alternative with which to calibrate the isotopic paleothermometer there. Still there are useful arguments coming from the isotopic composition of the air bubbles [Caillon et al., 2001], and from constraints with respect to ice core chronologies [Parrenin et al., 2001]. They converge toward the idea that the observed present-day spatial slope can be used to interpret Antarctic isotopic profiles [Petit et al., 1999; Jouzel et al., 2001]. This idea is also supported by atmospheric General Circulation Models (GCMs) as shown by Krinner et al. [1997] and by isotopic 


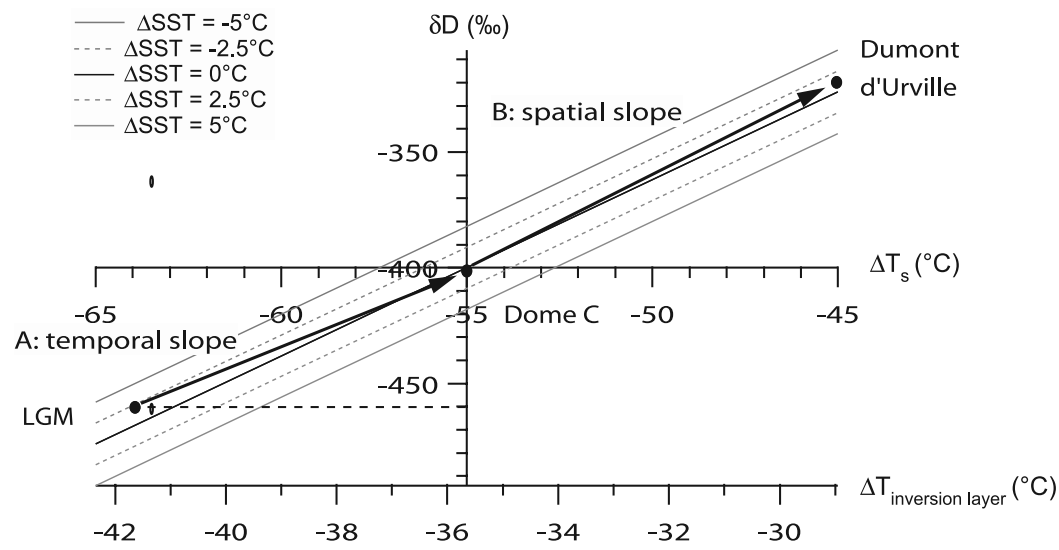

Figure 2. This figures illustrates the influence of the source temperature on the isotopic content of the Antarctic precipitation. Line B corresponds to the observed present-day spatial slope between Dumont d'Urville and Dome $\mathrm{C}$ expessed with respect to the temperature of snow formation (i.e., above the inversion layer). Line A represents the temporal slope assuming that the temperature change at the oceanic source is half that at the Dome C site. See color version of this figure at back of this issue.

GCMs which include the explicit modeling of water stable isotopes [Jouzel et al., 1994; Hoffmann et al., 2000; Delaygue et al., 2000; Werner et al., 2001].

[5] Our main objective here is to put these various arguments together in order to quantify the uncertainties associated with the conventional interpretation of isotopic records from Antarctic cores. This article complements, for Antarctica, the review published by Jouzel et al. [1997] which focused on Greenland ice records. We begin by briefly summarizing how simple isotopic models can easily be used to illustrate that spatial and temporal slopes can differ, pointing in particular to the possible influence of the origin and seasonality of precipitation. Examining these two aspects separately, we show that they are not likely to cause large differences between the spatial and temporal slopes in Antarctica. We then discuss other arguments linked to ice core chronologies [Parrenin et al., 2001], isotopic measurements in air bubbles [Caillon et al., 2001] and paleothermometry [Salamatin et al., 1998].

[6] We note here that the notion of temporal slope covers different timescales. The seasonal slope is deduced from the comparison of the isotope and temperature yearly cycles at a given site as derived, for example, by van Ommen and Morgan [1997] for the Law Dome near coastal site in East Antarctica (Figure 1). The short term (interannual) slope is based on the comparison of mean annual isotope and temperature values at sites where temperature records are available [see, for example, Jouzel et al., 1983], whereas the long term slope mainly refers to glacial-interglacial changes. As discussed by Jouzel et al. [1997], these three types of slopes generally differ (see discussion below). In this article, our assessment deals with the comparison between the spatial slope (defined in the region where the site is located) and the long term temporal slope. It is also important to note that some uncertainty is associated with the estimation of the spatial slope for a given region and that this spatial slope may vary from one region to another in Antarctica. For example, slopes of $6.04 \% / /{ }^{\circ} \mathrm{C}$ for $\delta \mathrm{D}$ and $0.75 \%{ }^{\circ} \mathrm{C}$ for $\delta^{18} \mathrm{O}$ (defined with respect to surface temperature, $\mathrm{T}_{\mathrm{s}}$ ) are used for interpreting Dome C and Vostok isotopic profiles. Recent estimates [Delmotte, 1997] suggest that those values are not defined to better than $\pm 10 \%$; they clearly may be higher in other regions of Antarctica, e.g. up to $1 \% 0 /{ }^{\circ} \mathrm{C}$ for $\delta^{18} \mathrm{O}$ in some areas.

\section{Main Factors Influencing the Isotope/ Temperature Temporal Slope}

[7] The main features of the distribution of water isotopes can be understood with a simple Rayleigh model that takes into account the isotopic fractionation processes occuring in an isolated air parcel traveling from an oceanic source toward a polar region [Dansgaard, 1964]. Such fractionations take place during most phase transitions experienced by water during its atmospheric cycle. They arise from differences both between the saturation vapor pressure of $\mathrm{HDO}$ or $\mathrm{H}_{2}{ }^{18} \mathrm{O}$ with respect to $\mathrm{H}_{2}{ }^{16} \mathrm{O}$ (the equilibrium effect), and between their molecular diffusivity in air (the kinetic effect). These simple models explain present-day observations over Antarctica well provided that the strong temperature inversion which characterizes central Antarctica [Robin, 1977] is taken into account [Jouzel and Merlivat, 1984]. As noted by many authors [see Jouzel et al., 1997, and references therein], these Rayleigh models first point to the combined influence of the temperature of the oceanic source $\left(\mathrm{T}_{\mathrm{w}}\right)$ and of the temperature of condensation $\left(T_{c}\right)$ on the isotopic content of precipitation. For example, (Figure 2) a parallel change in $T_{c}$ and $T_{w}$ will result in an increase of $\mathrm{R}_{\text {slopes }}$ [Aristarain et al., 1986; Boyle, 1997]. To illustrate this point, we use the formulation derived by Stenni et al. [2001] for the EPICA Dome C site in central East Antarctica. We assume [Jouzel and Merlivat, 1984] that the snow is formed just above the inversion layer which allows one to relate $\Delta \mathrm{T}_{\mathrm{c}}$ and $\Delta \mathrm{T}_{\mathrm{s}}$ through $\Delta \mathrm{T}_{\mathrm{c}}=0.67 \Delta \mathrm{T}_{\mathrm{s}}$. Using the mixed cloud isotopic model [Ciais and Jouzel, 1994] allows expression of the deuterium change at the site, $\Delta \delta \mathrm{D}$ as :

$$
\Delta \delta \mathrm{D}=7.6 \Delta \mathrm{T}_{\mathrm{s}}-3.6 \Delta \mathrm{T}_{\mathrm{w}}+\text { Corr }_{\text {ocean }}
$$


where Corr $_{\text {ocean }}$ is a correction due the change in the isotopic content of the oceanic source (see discussion below). A deuterium change of $60 \%$ o (including the oceanic correction), typical of the glacial-interglacial transition in central Antarctica, will be interpreted as a $\Delta \mathrm{T}_{\mathrm{s} \text { (spat) }}$ of $7.9^{\circ} \mathrm{C}$ if the dependence on the source temperature is neglected, as is done in the conventional interpretation. In contrast, we illustrate in Figure $2 \mathrm{a}$ case for which the change in $\Delta \mathrm{T}_{\mathrm{s}}$ is accompanied by a concurrent change in $\Delta \mathrm{T}_{\mathrm{w}}$ of half its size. We thus assume a polar amplification of the oceanic change by a factor of two roughly consistent with glacial interglacial climate simulations performed in the frame of the Paleoclimate Model Intercomparison Project [Pinot et al., 1999]. The resulting estimate of $\Delta \mathrm{T}_{\mathrm{s}}$ then increases to $10.3{ }^{\circ} \mathrm{C}\left(\mathrm{R}_{\text {slopes }}=1.31\right.$ as illustrated in Figure 2$)$. In quite the same way, the seasonal change in the origin of the precipitation has an impact on the seasonal slope. This impact may be large in particular for coastal sites (e.g., V. Masson-Delmotte et al., Recent climate variability in coastal eastern Antarctica from 1930 to 1990: An abrupt atmospheric circulation change in the 1970s archived in Law Dome DE08-2 ice core deuterium excess record, submitted to Climate and Dynamics, 2002) and, for this reason, the seasonal slope should not be used to estimate long term glacial-interglacial climatic changes.

[8] Many other factors obviously can influence $R_{\text {slopes }}$. These can be linked to other source characteristics controlling the evaporation kinetics such as relative humidity and wind speed [Merlivat and Jouzel, 1979] or to the microphysical processes prevailing in clouds such as the saturation value at snow formation [Fisher, 1991]. They can result from changes in the seasonality and intermittency of precipitation fallout which both bias the temperature sampling, or to wind erosion [Gallée et al., 2001] which can affect the isotopic signal differenly for an interglacial than for a glacial. Also, as the spatial slope is defined with respect to $T_{s}$, any change in the strength of the vertical inversion, for example, between a glacial and an interglacial, will influence $\mathrm{R}_{\text {slopes }}$. Changes in cyclonic activity [Holdsworth, 2001] and in the ratio between advection by the mean circulation and eddy transport [Eriksson, 1965; Hendricks et al., 2000, Noone and Simmonds, 2002] can also play a role, suggesting, in particular that the temporal slope can increase inland Antarctica [Hendricks et al., 2000; Kavanaugh and Cuffey, 2003]. The influence of most of these parameters has been systematically investigated for Greenland snow [Jouzel et al., 1997], pointing out the key role of the moisture origin and of the precipitation seasonality. We now successively examine the influence of these two parameters for Antarctica.

\section{Influence of the Origin of the Antarctic Precipitation}

[9] There are two complementary methods to assess the influence of the origin of a precipitation on its isotopic content. First the combined measurement of both $\delta \mathrm{D}$ and $\delta^{18} \mathrm{O}$ enables the calculation of a second order isotopic parameter, the deuterium excess $\left(\mathrm{d}=\delta \mathrm{D}-8 \times \delta^{18} \mathrm{O}\right)$ which depends on the temperature and relative humidity of the evaporative source (and, to a lesser degree, on the wind speed) controlling the kinetics of the phase change
[Merlivat and Jouzel, 1979]. In turn this parameter contains information about conditions prevailing in these source regions. Second, it is possible to perform GCM experiments in which the origin of the precipitation, and in most experiments its isotopic composition, is tagged and then followed from its source to the precipitation site. This approach has now been applied in several experiments addressing the relationship between the origin and the isotopic content of present-day antarctic precipitation [Koster et al., 1992; Noone and Simmonds, 2002] and glacial climates [Delaygue et al., 2000; Werner et al., 2001]. Both methods suggest that the moisture origin has limited impact on the interpretation of glacial-interglacial isotopic changes observed in inland Antarctica.

[10] To illustrate the first approach, we compare the Vostok temperature records reconstructed respectively by Petit et al. [1999] and Vimeux et al. [2002]. Petit et al. [1999] applied the conventional approach for calculating $\Delta \mathrm{T}_{\mathrm{s} \text { (spat) }}$ as $\left(\Delta \delta \mathrm{D}-\mathrm{Corr}_{\text {ocean }}\right) / 6.04$. Corr $_{\text {ocean }}$ is the correction applied for the change, $\Delta \delta \mathrm{D}_{\text {ocean }}$, in the deuterium composition of the ocean resulting from the waxing and the waning of the continental ice sheets during the last four climatic cycles. It is calculated as $\operatorname{Corr}_{\text {ocean }}=8 \times$ $\Delta \delta^{18} \mathrm{O}_{\text {ocean }}$ using the $\delta^{18} \mathrm{O}$ oceanic record from Bassinot et al. [1994] after appropriate scaling. Vimeux et al. [2002] used a modeling approach based on a Rayleigh type model [Ciais and Jouzel, 1994] and on the availability of both deuterium and oxygen 18 profiles. This approach is essentially a linear inversion procedure that directly accounts for the oceanic correction. It allows for the extraction of both $\Delta \mathrm{T}_{\mathrm{s}}$, denoted hereater $\Delta \mathrm{T}_{\mathrm{s}(\mathrm{inv})}$, and $\Delta \mathrm{T}_{\mathrm{w}}$ from the set of isotopic parameters (see Cuffey and Vimeux [2001] and Stenni et al. [2001] for a detailed description of the inversion method, which differs slightly between the two articles). Unlike the "isotopic paleothermometer" which relies on present-day observations, this inversion is thus a purely model based approach.

[11] At this point it is worth noting that the oceanic correction was incorrectly applied in Petit et al. [1999] and in previous estimates of the Vostok temperature record. It did not account for the fact that the influence of isotopic change at the ocean surface weakens as an air mass becomes isotopically depleted. In a Rayleigh model describing the isotopic behavior of an air mass from its oceanic origin to the precipitation site, the isotopic content of precipitation (here $\delta \mathrm{D}_{\text {ice }}$ ) can be written $1+\delta \mathrm{D}_{\text {ice }}=F \times$ $\left(1+\delta \mathrm{D}_{\text {ocean }}\right)$, where $F$ is a function of climatological parameters and fractionation coefficients only. Applying this equation for present-day $\left(\delta \mathrm{D}_{\mathrm{ocean}(0)}\right)$ and for a certain period in the past, $\delta \mathrm{D}_{\text {ocean }(\mathrm{t})}=\delta \mathrm{D}_{\text {ocean }(0)}+\Delta \delta \mathrm{D}_{\text {ocean }}$, shows that Corr $_{\text {ocean }}$ equals $\Delta \delta \mathrm{D}_{\text {ocean }} \times\left(1+\delta \mathrm{D}_{\text {ice }}\right) /\left(1+\Delta \delta \mathrm{D}_{\text {ocean }}\right)$ and not $\Delta \delta \mathrm{D}_{\text {ocean }}$ as previously used in the interpretion of Vostok records. Independently, Kavanaugh and Cuffey [2003] have recently pointed out to such an incorrect estimation of the oceanic correction, and have proposed a similar approach. As illustrated in Figure 3, this would have only a minor impact if the temperature record had been inferred from the $\delta^{18} \mathrm{O}$ ice record $\left(1+\delta^{18} \mathrm{O}_{\text {ice }}\right.$ is very close to 1$)$. This is not the case for the deuterium correction as $1+$ $\delta \mathrm{D}_{\text {ice }}$ is between 0.5 and 0.6 in Central East Antarctica. Consequently, the glacial-interglacial deuterium oceanic correction, which in Petit et al. [1999] is slighly below 


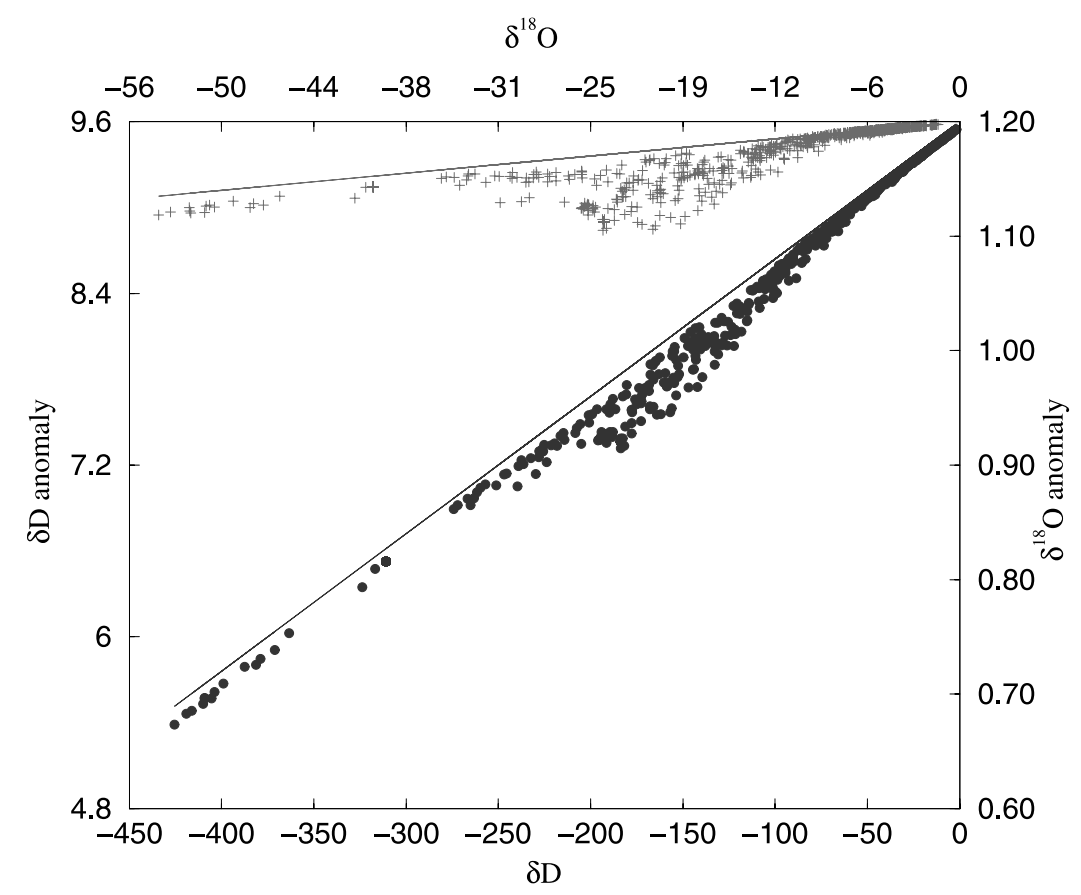

Figure 3. This plot illustrates how the oceanic correction can be estimated from a simple linear relationship directly derived from a Rayleigh type model. The points represent the oceanic correction as calculated from the difference between two GCM experiments performed by Delaygue [2000], one corresponding to the Last Glacial Maximum $\left(\delta \mathrm{D}=13.6 \% ; \delta^{18} \mathrm{O}=1.7 \%\right)$ and the other to modern conditions $\left(\delta \mathrm{D}=4 \% ; \delta^{18} \mathrm{O}=0.5 \%\right)$. The differences between thes two runs are calculated for each model grid point and reported as $\delta \mathrm{D}$ anomaly (in blue, left scale) and $\delta^{18} \mathrm{O}$ anomaly (in red, right scale). The two lines are directly derived from a Rayleigh type model applying the formula derived in section 3 to calculate Corr ocean (see text). See color version of this figure at back of this issue.

$10 \%$ for the Vostok site, decreases to $\sim 5.5 \%$ when correctly calculated (Figure 3 ).

[12] Our reasoning, which is based on a simple model, is fully confirmed using an isotopic GCM, as shown by Delaygue [2000] who performed, with the isotopic version of the NASA/GISS GCM [Jouzel et al., 1987a], two experiments which differed only by a change in the deuterium $(9.6 \%)$ and oxygen $18(1.2 \%)$ content of surface oceanic waters. As fully discussed by Jouzel et al. [1987a], this GCM correctly simulates present-day Antarctic climate as well the spatial and temporal $\delta \mathrm{D}$ and $\delta^{18} \mathrm{O}$ The resulting deuterium contours (Figure 1 ) show that the difference between the predicted $\delta D_{\text {ice }}$ of these two experiments weakens poleward with lowest deuterium changes in Central East Antarctica. These GCM estimates are reported in Figure 3 as a function of either $\delta D_{\text {ice }}$ or $\delta^{18} \mathrm{O}_{\text {ice }}$. Values are quite similar to those calculated from the above formula (Figure 3), which in this diagram lie practically on a straight line. This similarity is as expected because all atmospheric fractionation processes are independent of the isotopic concentrations themselves (small departures with respect to this line are due to the contribution of water vapor evaporating over continents). The simple model estimation can thus effectively be used to estimate Corr ocean $_{\text {. }}$

[13] For the sake of the comparison between the two methods for estimating Vostok temperature changes, this correct approach has been followed in the present work, and we apply it to calculate $\Delta \mathrm{T}_{\mathrm{s} \text { (spat) }}$ (Figure 4 , thick continuous line). The inferred record only slightly differs (by no more than $0.6^{\circ} \mathrm{C}$ ) from the temperature record (not shown) presented in Petit et al. [1999]. The estimate obtained by the inversion procedure is also reported in Figure 4. The inversion procedure in which there is an attempt to account for the moisture source changes [Vimeux et al., 2002] and the conventional approach in which the influence of those changes is ignored, provide results very close to each other. For example the amplitudes of the successive glacialinterglacial changes are slightly larger when estimated by the conventional approach but by no more than $\sim 10 \%$ on the average (with some differences from one cycle to another). As previously noted by Cuffey and Vimeux [2001], the most noticable difference occurs during glacial inceptions with the consequence that applying a deuteriumexcess correction improves the degree of co-variation between carbon dioxide and temperature.

[14] The correction due to source temperature changes alone increases the glacial - interglacial change at Vostok by up to $2^{\circ} \mathrm{C}$ [Vimeux et al., 2002]. Indeed the spatial slope derived from the inversion $\left(7.1 \% /{ }^{\circ} \mathrm{C}\right)$ is higher than the observed one $\left(6.04 \%{ }^{\circ} \mathrm{C}\right)$ used by Petit et al. [1999]. This difference, roughly compensating for the source correction, explains the smaller difference observed in Figure 4 between $\Delta \mathrm{T}_{\mathrm{s} \text { (spat) }}$ and $\Delta \mathrm{T}_{\mathrm{s} \text { (inv). }}$. Note that glacial-interglacial estimates of $\Delta T_{s}$ inferred from the EPICA Dome $\mathrm{C}$ core are also quite similar (i.e., $\sim 9^{\circ} \mathrm{C}$ between the LGM and the Holocene optimum) if obtained either by the conventional approach [Jouzel et al., 2001], or by accounting for changes 


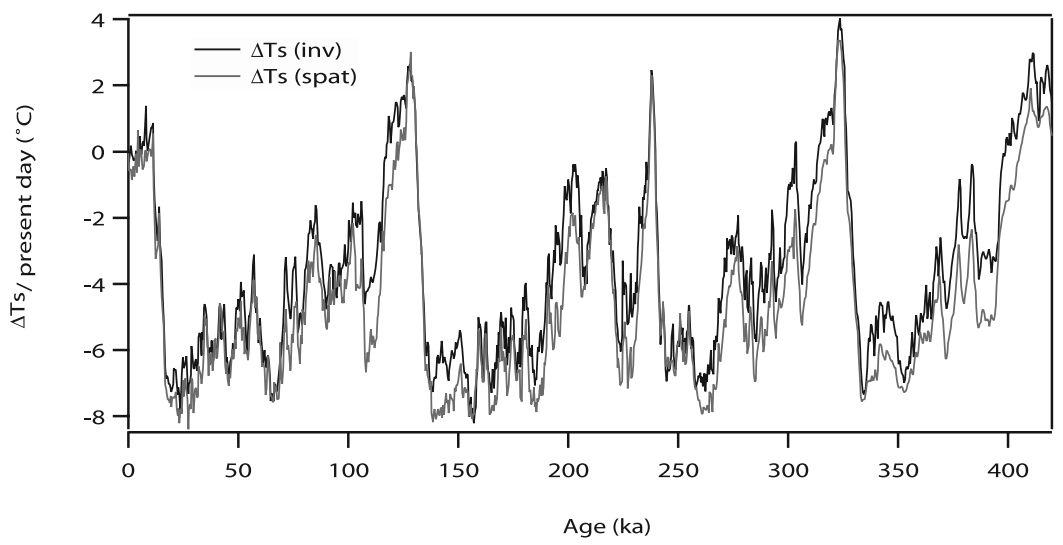

Figure 4. Vostok temperature changes from present-day values back to $420 \mathrm{kyr}$ BP, estimated either $\left(\Delta \mathrm{T}_{\mathrm{s} \text { (spat) }}\right.$ in red) by the conventional approach based on the $\delta \mathrm{D}$ profile alone [Petit et al., 1999] accounting correctly for the oceanic correction (see text), or $\left(\Delta \mathrm{T}_{\mathrm{s} \text { (inv) }}\right.$ in green) by the inverse method based on the use of deuterium-excess to account for moisture source changes [Vimeux et al., 2002]. See color version of this figure at back of this issue.

in source temperature [Stenni et al., 2001]. The explanation given for Vostok also applies to EPICA Dome C (the model derived spatial slope for Dome $\mathrm{C}$ is $7.6 \%{ }^{\circ} \mathrm{C}$, see equation given in section 2).

[15] Experiments performed with the isotopic version of the NASA/GISS model lead to a similar conclusion [Delaygue et al., 2000]. Unlike simple models that generally consider a unique source, the GCM enables the explicit tagging of the moisture provided by multiple sources (19 in each hemisphere in this particular study). This approach confirms the simple model result that moisture originating from warmer sources provides precipitation with a lower $\delta_{\mathrm{p}}$. It also shows the impact of atmospheric circulation on $\delta_{\mathrm{P}}$, which also depends on the distance between the source and the precipitation site. However, due to changes in the contributions from those various sources, the Antarctic mean source temperature does not significantly change between modern and glacial climates, being $2^{\circ} \mathrm{C}$ warmer than for present-day when using CLIMAP SST reconstruction and almost unchanged when the tropics are cooled with respect to CLIMAP [Delaygue et al., 2000]. This results in a relatively limited increase of $\mathrm{R}_{\text {slopes }}(10$ to $30 \%$ ). Note however that glacial simulations do not show a good agreement with deuterium excess observations in these GCM experiments. This may arise from unrealistic latitudinal SST and sea ice reconstructions, which would then add some uncertainty to this estimate of $R_{\text {slopes. }}$.

\section{Influence of the Seasonality of the Antarctic Precipitation}

[16] There are only limited data on the seasonality of present-day precipitation for inland Antarctica [Ekaykin et al., 2002] and practically no information available for a period such as the LGM. This information can only be derived from GCM experiments as first closely examined by Krinner et al. [1997]. For this purpose, these authors implemented the LMDz stretched-grid GCM adapted to have a high resolution in polar regions. They calculated the condensation temperature as the precipitation weighted temperature of the model layers where the precipitation forms. The difference between the glacial-interglacial change in the condensation temperature and $\Delta \mathrm{T}_{\mathrm{s}}$ gives thus an indication of the bias introduced by seasonality and inversion when interpreting the isotopic signal of polar precipitation. The bias due to seasonality is large for Greenland where the model does not simulate a clear seasonality of present-day precipitation, a feature also inferred from pit studies [Shuman et al., 1995], but shows a clear summer precipitation maximum for the LGM. These seasonality changes can largely explain the fact that using the presentday spatial slope for interpreting GRIP and GISP2 isotopic profiles underestimates glacial-interglacial temperature changes by a factor of two [Krinner et al., 1997; Werner et al., 2000]. On the East Antarctic Plateau, however, the condensation temperature seasonal cycle remains close to the modern level and there is only a weak bias due to seasonality, and little influence of other local parameters such as the intermittency of the precipitation and the strength of the inversion.

[17] Using the same diagnoses, Delaygue et al. [2000] arrived at a similar conclusion for the GISS model in which present-day Antarctic precipitation is characterized by a weak seasonal cycle. Glacial conditions decrease the winter contribution to annual precipitation inducing a limited $15 \%$ decrease in $\mathrm{R}_{\text {slopes. }}$ Overall the combined influence of the origin (increase of 10 to $30 \%$ ) and seasonality of the precipitation does not exceed $\sim 15 \%$ in this NASA/GISS model. Werner et al. [2001] also noted that, in the ECHAM model, glacial-interglacial changes in the seasonal distribution of precipitation are much smaller for Antarctica than for Greenland, and have thus less influence on $\mathrm{R}_{\text {slopes. }}$ We attribute this difference to the particular location of the Greenland ice sheet next to the highly variable polar front and to the influence of the Laurentide at the LGM. In contrast, Antarctica boundary conditions are much less affected for and around Antarctica which keeps its overall circular symetry between LGM and present-day conditions. In turn, whereas seasonality changes are the main explanation of the underestimation of glacial-interglacial Greenland temperature changes [Krinner et al., 1997; Werner et al., 
2000], all available GCM experiments point to a limited impact of these processes on central Antarctica.

\section{Estimating the Temporal Slope From Isotopic GCMs}

[18] Experiments and diagnoses designed to identify separately the influence on $R_{\text {slopes }}$ of specific factors such as the origin and seasonality of the precipitation have been performed only recently. One initial objective of isotopic GCMs was to provide a direct comparison between spatial and temporal slopes by simulating different climatic periods. This appraoch was pioneered by Joussaume and Jouzel [1993] from present-day and LGM simulations using the LMD isotopic model. However, the simulation was limited to a perpetual January and July which did not enable a reliable estimate of $R_{\text {slopes }}$ at the yearly scale.

[19] Various present-day and LGM experiments covering several years were then performed using both the NASA/ GISS [Jouzel et al., 1994] and the ECHAM Hamburg [Hoffmann and Heimann, 1997] isotopic models. As far as Antarctica is concerned, the NASA/GISS model predicts spatial slopes lower than temporal slopes over most Antarctic grid points, but whereas the difference is limited over East Antarctica $\left(\mathrm{R}_{\text {slopes }}=0.80\right)$, it is much larger for West Antarctica $\left(\mathrm{R}_{\text {slopes }}=0.6\right)$. However, in this latter region there are large glacial-interglacial changes in the prescribed topography of the ice cap that are probably not realistic and bias the estimate of $R_{\text {slopes }}$ (which does not account for local changes such as the altitude of the site). Note also that the present-day spatial slope predicted with the NASA/GISS model is higher than the one observed over East Antarctica quite probably because of the very weak simulated inversion strength. In turn the comparison with data is good when the temperature of condensation, $\mathrm{T}_{\mathrm{c}}$, is considered, but deteriorates when $\mathrm{T}_{\mathrm{s}}$ is taken into account [Jouzel et al., 1994]. Although this explanation is satisfying from an isotopic point of view, as it is $T_{c}$ and not $T_{s}$ that governs the isotopic content of the precipitation, this discrepancy between observed and predicted inversion strength should be kept in mind. In contrast, ECHAM results, obtained with a more realistic topography and with higher spatial resolution, show an excellent agreement, that is, within $\sim 5 \%$, between observed and predicted $\mathrm{S}_{\text {spat }}$ both for East and West Antarctica [Hoffmann and Heimann, 1997]. Comparison with the LGM run [Hoffmann et al., 2000] provides estimates of $\mathrm{R}_{\text {slopes }}$ around 0.9 (0.88 and 0.91 over East and West Antarctica respectively). From this latter experiment, we can thus be confident in the fact that temporal and spatial slopes are relatively close to each other in Antarctica when the glacial-modern change is considered. Experiments has now been completed by a series of isotopic simulations with various boundary conditions corresponding to climates intermediate between present-day and the LGM. These new experiments (G. Hoffmann et al., manuscript in preparation, 2003) generally confirm the results presented by Hoffmann et al. [2000].

[20] Finally, although not based on a GCM approach, the recent modeling performed by Hendricks et al. [2000] is worth mentioning in this section. These authors have developed a one-dimensional model of meridional water vapor transport to evalute the factors that control spatial and temporal variations of $\delta \mathrm{D}$ and $\delta^{18} \mathrm{O}$ in global precipitation.
They found a good agreement between $S_{\text {spat }}$ and $S_{\text {temp }}$ for inland sites such as Vostok and South Pole but significantly lower $\mathrm{S}_{\text {temp }}$ for more coastal regions. Interestingly, this feature of $S_{\text {temp }}$ increasing inland is also seen, but much less pronounced, in GCM experiments [Hoffmann et al., 2000; Jouzel et al., 2000].

\section{Ice Core Chronologies and Temperature Changes}

[21] One way to derive Antarctic ice core chronologies [Ritz, 1992; Petit et al., 1999; Schwander et al., 2001] is to evaluate the thickness of the successive annual layers by multiplying the rate of accumulation by the thinning function, that is, to combine an accumulation history and an ice flow model. As the thinning is accurately known, at least in the upper part of an ice sheet, any chronological information adds constraints to the change of accumulation through time. Moreover, there are good arguments that, over the Antarctic Plateau, the accumulation rate is governed by the amount of water vapor available at the level where precipitation forms just above the inversion [G.d.Q Robin, 1977]. As a first approximation, this rate can thus be estimated as being proportional to the derivative of the water vapor saturation pressure above the precipitation site [Jouzel et al., 1987b]. It appears to follow, therefore, that temperature information at a given site can be inferred from the knowledge of accumulation change through time.

[22] This approach has first been exploited for the Vostok core by comparing two different estimates of accumulation change during the last climatic cycle. One uses the beryllium 10 record assuming that the beryllium 10 fallout [Raisbeck et al., 1987] is constant through time, that is, that snow accumulation is inversely proportional to ${ }^{10} \mathrm{Be}$ concentration. The other uses the vapor pressure link with an estimate of temperature change based on the present-day spatial slope. The noticable similarity between these two estimates of accumulation change was taken as an argument in favor of this conventional interpretation of the Vostok isotopic profile [Jouzel et al., 1989].

[23] This reasoning is certainly too simplistic. Accumulation and temperature are clearly linked over Antarctica, but the proportionality with the derivative of the saturation vapor pressure is not warranted and other parameters than temperature such as the intensity of the atmospheric circulation may influence accumulation rates. With this in mind, Parrenin et al. [2001] recently developed an inverse method for dating the Vostok core, with the main assumption being that the number of precessional cycles can correctly be counted. Rather than assuming a linear relationship between the ice deuterium content and temperature with a prescribed slope, they simply use a second-order relationship with two free parameters, thus making no assumptions about the amplitude of the glacial-interglacial temperature change. They kept the assumption linking accumulation to temperature change through the vapor pressure, and assumed that the present-day accumulation upstream is a second-order function of the distance to Vostok. They also discussed the possible influence of atmospheric circulation changes. In turn, the application of the inverse method using available chronological constraints (see Parrenin et al. [2001] for a detailed description) provides information both on temper- 
ature and accumulation changes. Using the spatial slope slightly underestimates temperature changes with respect to the inverse method but probably by no more than 10 to $20 \%$ over the full range of observed $\delta \mathrm{D}$ changes. In this same line, we note the result derived by Schwander et al. [2001] from their dating of the EPICA Dome $\mathrm{C}$ core. These authors inferred that using the spatial slope also underestimates the glacial-interglacial surface temperature change at this site by about $20 \%$ (depending on the reference taken for the $\mathrm{S}_{\text {spat }}$ ).

\section{Constraints From Gas Age-Ice Age Difference}

[24] Because of compaction, the density of snow increases with depth in the upper part of an ice sheet, which is made up of consolidated snow commonly referred to as firn. Air circulates in the firn and is trapped in its lower part, the entrapped air being thus younger than the ice matrix. Firnification models show that the age difference between the ice and the entrapped air, $\Delta_{\text {age, }}$, depends on both accumulation and temperature. Schwander et al. [1997] used this property to corroborate the large glacial-interglacial change inferred from central Greenland borehole temperature profiles. To do so, they estimated $\Delta_{\text {age }}$ assuming a small phase lag between variations in the Greenland surface temperature and the atmospheric methane. Severinghaus et $a l$. [1998] followed a similar approach but estimated $\Delta_{\text {age }}$ in a more straigthforward way, that is, taking advantadge of the fact that air composition is slightly modified during firnification processes by physical processes such as gravitational and thermal fractionation. In particular, due to much faster diffusion of gases than heat, a detectable anomaly in the isotopic composition of nitrogen and argon is created in the case of a rapid temperature change.

[25] Although the Antarctic climate is not characterized by such abrupt changes as observed in Greenland, Caillon et al. [2001] have undertaken a detailed study of the most rapid isotopic warming event that occurred between 107 and $108 \mathrm{kyr} \mathrm{BP}$, at the end of a cold period that was slightly milder than the LGM. They successfully measured a small but detectable anomaly in both nitrogen and argon isotopic compositions resulting possibly from a gravitational signal due to a change in the firn thickness. The position of this anomaly when compared to the deuterium profile gives a direct estimate of the depth at which air bubbles are trapped (close-off depth). From this estimate, it is inferred that the use of the spatial slope slightly underestimates temperature changes but by no more than $20 \pm 15 \%$ (i.e., $R_{\text {slopes }}=1.20$ ). One weakness of this approach is that it uses the accumulation change based on the conventional interpretation of the Vostok deuterium profile. To circumvent this difficulty, F. Parrenin et al. (manuscript in preparation, 2003) use the information on the close-off depth as an additional constraint in their inverse model then accounting for concurrent accumulation and temperature changes around this event. This improved interpretation essentially confirms the result published by Caillon et al. [2001] with, however a slightly lower estimate of $\mathrm{R}_{\text {slopes }}(1.15)$.

\section{Borehole Paleothermometry}

[26] Interpretation of borehole temperature profiles has been extensively used to estimate glacial-interglacial tem- perature changes in Central Greenland [Cuffey et al., 1995; Johnsen et al., 1995; Dahl-Jensen et al., 1998]. The application of this method is not straigthforward for central sites in east Antarctica because the temperature signal preserved in the ice highly damped by heat diffusion because of the very low accumulation. Indeed a straightforward application of an inverse method clearly shows that no useful information can be retrieved at such a site as Vostok [Rommelaëre, 1997]. To overcome this problem, Salamatin et al. [1998, and references herein] developed an inverse procedure based on the assumption that the inferable components of the surface temperature at Vostok can be expressed as a sum of harmonics of Milankovitch periods. Application of this technique confirmed, in general, the conventional approach of using the present-day spatial slope $\left(\mathrm{R}_{\text {slopes }}\right.$ of $\left.\sim 1\right)$ with however a significant mismatch between modeled and borehole temperatures [Salamatin et al., 1998]. We note here that this approach relies on the assumption of constant phase between orbital forcing and Vostok temperature changes which is clearly questioned in the recent work of Parrenin et al. [2001] and by the nonlinearities of climate dynamics.

[27] This mismatch decreases noticeably if surface temperature is assumed to undergo more intensive precession oscillations than temperature at the inversion level. With this additional assumption, it is inferred that the magnitude of the surface temperature was greater by $\sim 30 \%\left(\mathrm{R}_{\text {slopes }}=\right.$ 1.3 ) and even by up to $50 \%$ depending on assumptions made for the inversion procedure. The fact that Vostok paleothermometry provides such high estimates of glacialinterglacial temperature changes is now often cited. However, we would like to draw attention to the fact that we have currently no clear argument to support this additional assumption on which this higher estimate is based.

\section{Discussion and Conclusion}

[28] We will focus the discussion on the East Antarctic Plateau for which we have both model and empirical estimates of glacial-interglacial temperature changes, whereas only the former are currently available for more coastal sites and for West Antarctica as a whole.

[29] We have first separately examined the influence on $\mathrm{R}_{\text {slopes }}$ of glacial-interglacial changes in two key parameters, the origin and the seasonality of the precipitation. The use of the deuterium-excess information suggests a low influence of the former $\left(\mathrm{R}_{\text {slopes }}=\sim 1.1\right.$ at Vostok and $\sim 1$ at EPICA Dome C) which is also indicated by model results ( $\mathrm{R}_{\text {slopes }}$ between 1.1 and 1.3). The same is true for the seasonality as confirmed by modeling experiments using different GCMs (LMD, NASA/GISS and ECHAM). For example, changes in seasonality induce a limited decrease of $\mathrm{R}_{\text {slopes }}$ with the NASA/GISS model $\left(\mathrm{R}_{\text {slopes }}=\sim 0.85\right)$. Moreover, the influences of seasonality and origin of precipitation partially compensate one another in this experiment with an overall bias limited to $\sim 15 \%$. Other estimates based either on isotopic GCMs or on empirical approaches do not discriminate between the influence of the various parameters involved. Estimates based on the comparison of LGM and present-day isotopic GCM experiments give temperature changes slightly lower than the conventional approach $\left(\mathrm{R}_{\text {slopes }}=\sim 0.8\right.$ and 0.88 with the NASA/ 
GISS and ECHAM models, respectively). This is in contrast with the slightly higher temperature changes suggested by the information inferred both from ice core chronologies $\left(\mathrm{R}_{\text {slopes }}=\sim 1.2\right)$ and gas-age ice-age differences $\left(\mathrm{R}_{\text {slopes }}=\right.$ $\sim 1.15$ to 1.2 ). Taken together, these various approaches indicate values of $\mathrm{R}_{\text {slopes }}$ ranging between 0.8 and 1.2 . Overall, these estimates can be considered as consistent given the uncertainties associated with each of them and the fact that the present-day spatial slope itself is regionally dependent and, even for a given region, is probably not known to better than 10 to $20 \%$. We however note that other potential sources of uncertainties such as the possible changes in magnitude of advective/diffusive transport [Hendricks et al., 2000] have not been taken into account specifically, but only through our GCM experiments.

[30] The paleothermometer calibration based on the borehole temperature profile provides estimates outside this range $\left(\mathrm{R}_{\text {slopes }}\right.$ around 1.3 and up to 1.5$)$. We suggest that this discrepancy arises because the assumptions made to invert this temperature profile are not fully satisfied, in particular the existence of more intensive precession oscillations at the surface than in the atmosphere during glacial. We note however that other empirical estimates (dating and gas age/ice age constraints) point to slightly stronger temperature changes. We also note that the lowest estimate of $\mathrm{R}_{\text {slopes }}(0.80)$ was obtained with the low resolution NASA/ GISS GCM which did not provide a fully satisfying picture of the isotopic distribution for present-day (section 5). Thus, we propose a value of $1.1 \pm 0.2$ as our best current estimate of $R_{\text {slopes. }}$. We conclude that the evidence presently available indicates that the present-day spatial-slope can probably be taken, within -10 to $+20 \%$, as a surrogate for the temporal slope to interpret isotopic profiles from the East Antarctic Plateau. In addition, we now probably have a good understanding of why the situation differs between Central Greenland and the East Antarctic Plateau in this respect, the latter being much less affected than the former by glacial-interglacial changes in boundary conditions. This gives further confidence in our conclusion.

\section{Notation}

$\mathrm{T}_{\mathrm{S}} \quad$ Surface temperature site.

$\mathrm{T}_{\mathrm{c}}$ Condensation temperature.

$\mathrm{T}_{\mathrm{w}}$ Moisture source temperature.

$\mathrm{S}_{\text {spat }} \quad$ Spatial $\delta / \mathrm{T}$ slope.

$S_{\text {temp }}$ Temporal $\delta / T$ slope.

$\mathrm{R}_{\text {slopes }}$ Sspat/Stemp.

$\mathrm{T}_{\mathrm{s}(\mathrm{spat})} \quad$ Surface temperature site determined with Sspat.

$\mathrm{T}_{\mathrm{s} \text { (inv) }}$ Surface temperature site determined with the inversion of simple isotopic model.

$\delta \mathrm{D}, \delta^{18} \mathrm{O} \quad$ Isotopic content in per mill with respect to the Standard Mean Ocean Water.

$\delta_{\mathrm{P}} \quad$ Isotopic content of a precipitation (stands either for $\delta$ Dor for $\delta^{18} \mathrm{O}$ ).

d Deuterium excess defined as $\mathrm{d}=\delta \mathrm{D}-8 * \delta^{18} \mathrm{O}$.

$\Delta$ Difference between two time periods.

Corr $_{\text {ocean }}$ Correction due to change in oceanic $\delta$.

[31] Acknowledgments. We would like to thank Kurt Cuffey and two anonymous reviewers for their very useful suggestions, and Gabrielle Dreyfus for careful reading of the manuscript and fruitful discussions. This work is supported in France by the Programme National d'Études de la
Dynamique du Climat (PNEDC) and by the European program Pole-OceanPole (POP EVK2-2000-00089).

\section{References}

Aristarain, A. J., J. Jouzel, and M. Pourchet, Past Antarctic Peninsula climate (1850-1980) deduced from an ice core isotope record, Clim. Change, 8, 69-89, 1986.

Bassinot, F. C., L. D. Labeyrie, E. Vincent, X. Quidelleur, N. J. Shackleton, and Y. Lancelot, The astronomical theory of climate and the age of the Brunhes-Matuyama magnetic reversal, Earth Planet. Sci. Lett., 126, 91-108, 1994.

Boyle, E. A., Cool tropical temperatures shift the global $\delta^{18} \mathrm{O}-\mathrm{T}$ relationship: An explanation for the ice core $\delta^{18} \mathrm{O}$ borehole thermometry conflict?, Geophys. Res. Lett., 24, 273-276, 1997.

Caillon, N., J. P. Severinghaus, J. M. Barnola, J. C. Chappellaz, J. Jouzel, and F. Parrenin, Estimation of temperature change and of gas age-ice age difference, $108 \mathrm{kyr}$ BP, at Vostok, Antarctica, J. Geophys. Res., 106, $31,893-31,901,2001$

Ciais, P., and J. Jouzel, Deuterium and oxygen 18 in precipitation: An isotopic model including mixed cloud processes, J. Geophys. Res., 99, $16,793-16,803,1994$.

Cuffey, K. M., and F. Vimeux, Covariation of carbon dioxyde and temperature from the Vostok ice core after deuterium-excess correction, Nature, 421, 523-527, 2001.

Cuffey, K. M., G. D. Clow, R. B. Alley, M. Stuiver, E. D. Waddington, and R. W. Saltus, Large Arctic temperature change at the WinconsinHolocene glacial transition, Science, 270, 455-458, 1995.

Dahl-Jensen, D., K. Mosegaard, N. Gundestrup, G. D. Clow, S. J. Johnsen, A. W. Hansen, and N. Balling, Past temperatures directly from the Greenland ice sheet, Science, 282, 268-271, 1998.

Dansgaard, W., Stable isotopes in precipitation, Tellus, 16, 436-468, 1964. Delaygue, G., Relationship between the oceanic surface and the isotopic content of Antarctic precipitation: Simulations for different climates, Ph.D. thesis, Univ. of Aix-Marseille, Marseille, France, 2000.

Delaygue, G., J. Jouzel, V. Masson, R. D. Koster, and E. Bard, Validity of the isotopic thermometer in central Antarctica: Limited impact of glacial precipitation seasonality and moisture origin, Geophys. Res. Lett., 27, 2677-2680, 2000.

Delmotte, M., Enregistrements climatiques à Law-Dome: Variabilité pour les périodes récentes et pour la déglaciation, thèse, Univ. Joseph Fourier, Grenoble, France, 1997.

Ekaykin, A. A., V. Y. Lipenkov, N. I. Barkov, and J. R. Petit, Spatial and temporal variability in isotope composition of recent snow in the vicinity of Vostok Station: Implications for ice-corerecord interpretation, Ann. Glaciol., 35, 181-186, 2002.

Eriksson, E., Deuterium and oxygen-18 in deuterium and other natural waters: Some theoretical considerations, Tellus, 16, 498-512, 1965.

Fisher, D. A., Remarks on the deuterium excess in precipitation in cold regions, Tellus, Ser. B, 43, 401-407, 1991.

Gallée, H., G. Guyomarc'h, and E. Brun, Impact of snow drift on the Antarctic ice sheet surface mass balance: Possible sensitivity to snowsurface properties, Boundary Layer Meteorol., 99, 1-19, 2001.

Hendricks, M. B., D. J. De Paolo, and R. C. Cohen, Space and time variation of $\delta \mathrm{D}$ and $\delta^{18} \mathrm{O}$ in precipitation: Can paleotemperature be estimated from ice cores?, Global Biogeochem. Cycles, 14, 851-861, 2000.

Hoffmann, G., and M. Heimann, Water isotope modeling in the Asian Monsoon region, Quat. Int., 37, 115-128, 1997.

Hoffmann, G., V. Masson, and J. Jouzel, Stable water isotopes in atmospheric general circulation models, Hydrol. Processes, 14, 1385-1406, 2000 .

Holdsworth, G., Calibration changes in the isotopic thermometer according to different climatic states, Geophys. Res. Lett., 28, 2625-2628, 2001.

Johnsen, S. J., W. Dansgaard, and J. W. White, The origin of Arctic precipitation under present and glacial conditions, Tellus, Ser. B, 41, 452469, 1989.

Johnsen, S. J., D. Dahl-Jensen, W. Dansgaard, and N. Gundestrup, Greenland paleotemperatures derived from GRIP bore hole temperature and ice core isotope profiles, Tellus, Ser. B, 47, 624-629, 1995.

Joussaume, S., and J. Jouzel, Paleoclimatic tracers: An investigation using an atmospheric general circulation model under ice age conditions: 2 . Water Isotopes, J. Geophys. Res., 98, 2807-2830, 1993.

Jouzel, J., Calibrating the isotopic paleothermometer, Science, 286, 910911, 1999.

Jouzel, J., and L. Merlivat, Deuterium and oxygen 18 in precipitation: Modeling of the isotopic effects during snow formation, J. Geophys. Res., 89, 11,749-11,757, 1984.

Jouzel, J., L. Merlivat, J. R. Petit, and C. Lorius, Climatic information over the last century deduced from a detailed isotopic record in the South Pole snow, J. Geophys. Res., 88, 2693-2703, 1983. 
Jouzel, J., G. L. Russell, R. J. Suozzo, R. D. Koster, J. W. C. White, and W. S. Broecker, Simulations of the HDO and $\mathrm{H}_{2}{ }^{18} \mathrm{O}$ atmospheric cycles using the NASA/GISS general circulation model: The seasonal cycle for present-day conditions, J. Geophys. Res., 92, 14,739-14,760, 1987a.

Jouzel, J., C. Lorius, J. R. Petit, C. Genthon, N. I. Barkov, V. M. Kotlyakov, and V. M. Petrov, Vostok ice core: A continuous isotope temperature record over the last climatic cycle (160,000 years), Nature, 329, 402408, $1987 \mathrm{~b}$.

Jouzel, J., et al., A comparison of deep Antarctic ice cores and their implications for climate between 65,000 and 15,000 years ago, Quat. Res., 31, 135-150, 1989.

Jouzel, J., R. D. Koster, R. J. Suozzo, and G. L. Russell, Stable water isotope behavior during the LGM: A GCM analysis, J. Geophys. Res., 99, 25,791-25,801, 1994.

Jouzel, J., et al., Validity of the temperature reconstruction from ice cores, J. Geophys. Res., 102, 26,471-26,487, 1997.

Jouzel, J., G. Hoffmann, R. D. Koster, and V. Masson, Water isotopes in precipitation: Data/model comparison for present-day and past climates, Quat. Sci. Rev., 19, 363-379, 2000.

Jouzel, J., et al., A new $27 \mathrm{Ky}$ high resolution East Antarctic climate record, Geophys. Res. Lett., 28, 3199-3202, 2001.

Kavanaugh, J. L., and K. M. Cuffey, Space and time variation of $\delta^{18} \mathrm{O}$ and $\delta \mathrm{D}$ in Antarctic precipitation, revisited, Global Biogeochem. Cycles, 17(1), 1017, doi:10.1029/2002GB001910, 2003.

Koster, R. D., J. Jouzel, R. J. Suozzo, and G. L. Russell, Origin of July Antarctic precipitation and its influence on deuterium content: a GCM analysis, Clim. Dyn., 7, 195-203, 1992.

Krinner, G., C. Genthon, and J. Jouzel, GCM analysis of local influences on ice core $\delta$ signals, Geophys. Res. Lett., 24, 2825-2828, 1997.

Lorius, C., and L. Merlivat, Distribution of mean surface stable isotope values in East Antarctica. Observed changes with depth in a coastal area in Isotopes and Impurities in Snow and Ice, Proceedings of the Grenoble Symposium Aug./Sep. 1975, IAHS Publ., 118, 127-137, 1977.

Merlivat, L., and J. Jouzel, Global climatic interpretation of the DeuteriumOxygen 18 relationship for precipitation, J. Geophys. Res., 84, 50295033,1979

Noone, D., and I. Simmonds, Associations between $\delta^{18} \mathrm{O}$ of water and climate parameters in a simulation of atmospheric circulation for 1979-1995, J. Clim., 15, 3150-3169, 2002

Parrenin, F., J. Jouzel, C. Waelbroeck, C. Ritz, and J. M. Barnola, Dating the Vostok ice core by an inverse method, J. Geophys. Res., 106, 31,837-31,851, 2001.

Petit, J. R., et al., Climate and atmospheric history of the past 420000 years from the Vostok ice core, Antarctica, Nature, 399, 429-436, 1999.

Pinot, S., G. Ramstein, S. P. Harrison, I. C. Prenctice, J. Guiot, M. Stute, and S. Joussaume, Tropical paleoclimates at the last Glacial maximum Comparison of Paleoclimate Modeling Intercomparison Project (PMIP) simulations and paleodata, Clim. Dyn., 15, 857-874, 1999.

Raisbeck, G. M., F. Yiou, D. Bourles, C. Lorius, J. Jouzel, and N. I. Barkov, Evidence for two intervals of enhanced deposition in Antarctic ice during the last glacial period, Nature, 326, 273-277, 1987.
Ritz, C., Un modèle thermo-mécanique d'évolution pour le bassin glaciaire Antarctique Vostok-Glacier Byrd: Sensibilité aux valeurs des paramètres mal connus (in French), Ph.D. thesis, Univ. Joseph Fourier, Grenoble, France, 1992.

Robin, G. d. Q., Ice cores and climatic changes, Philos. Trans. R. Soc. London, Ser. B, 280, 143-168, 1977.

Rommelaere, V., Trois problèmes inverses en glaciologie (in French), Ph. D. thesis, Univ. Joseph Fourier, Grenoble, France, 1997.

Salamatin, A. N., V. Y. Lipenkov, N. I. Barkov, J. Jouzel, J. R. Petit, and D. Raynaud, Ice core age dating and paleothermometer calibration on the basis of isotopes and temperature profiles from deep boreholes at Vostok station (East Antarctica), J. Geophys. Res., 103, 8963-8977, 1998.

Schwander, J., T. Sowers, J. M. Barnola, T. Blunier, B. Malaizé, and A. Fuchs, Age scale of the air in the summit ice: Implication for glacial-interglacial temperature change, J. Geophys. Res., 102, 19,483-19,494, 1997.

Schwander, J., J. Jouzel, C. U. Hammer, J. R. Petit, R. Udisti, and E. Wolff, A tentative chronology of the EPICA Dome C ice core, Geophys. Res. Lett., 28, 4243-4246, 2001

Severinghaus, J. P., T. Sowers, E. Brook, R. B. Alley, and M. L. Bender, Timing of abrupt climate change at the end of the Younger Dryas interval from thermally fractionated gases in polar ice, Nature, 391, 141-146, 1998.

Shuman, C. A., R. B. Alley, S. Anandakrishnan, J. W. C. White, P. M. Grootes, and C. R. Stearns, Temperature and accumulation at the Greenland Summit: Comparison of high-resolution isotope profiles and satellite passive microwave brightess temperature trends, J. Geophys. Res., 100, 9165-9177, 1995.

Stenni, B., V. Masson, S. J. Johnsen, J. Jouzel, A. Longinelli, E. Monnin, R. Roethlisberger, and E. Selmo, An oceanic cold reversal during the last deglaciation, Science, 293, 2074-2077, 2001.

van Ommen, T. D., and V. Morgan, Calibrating the ice core paleothermometer using seasonality, J. Geophys. Res., 102, 9351-9357, 1997.

Vimeux, F., K. Cuffey, and J. Jouzel, New insights into Southern Hemisphere temperature changes from Vostok ice cores using deuterium excess correction, Earth Planet Sci. Lett., 203, 829-843, 2002.

Werner, M., U. Mikolajewicz, M. Heimann, and G. Hoffmann, Borehole versus isotope temperatures on Greenland: Seasonality does matter, Geophys. Res. Lett., 27, 723-726, 2000.

Werner, M., M. Heimann, and G. Hoffmann, Isotopic composition and origin of polar precipitation in present and glacial climate simulations, Tellus, Ser. B, 53, 53-71, 2001

N. Caillon, Scripps Institution of Oceanography, 8602 La Jolla Shores Drive, La Jolla, CA 92093-0244, USA.

G. Delaygue, CEREGE, Europôle de l'Arbois, B. P. 80, F-13545 Aix en Provence, France.

G. Hoffmann, J. Jouzel, V. Masson-Delmotte, and F. Vimeux, IPSL/ LSCE, CE Saclay, F-91191 Gif sur Yvette, France. (jouzel@1sce.saclay. cea.fr)

F. Parrenin, OMP/LEGOS, 18 Avenue Edouard Belin, F-31401 Toulouse, France. 


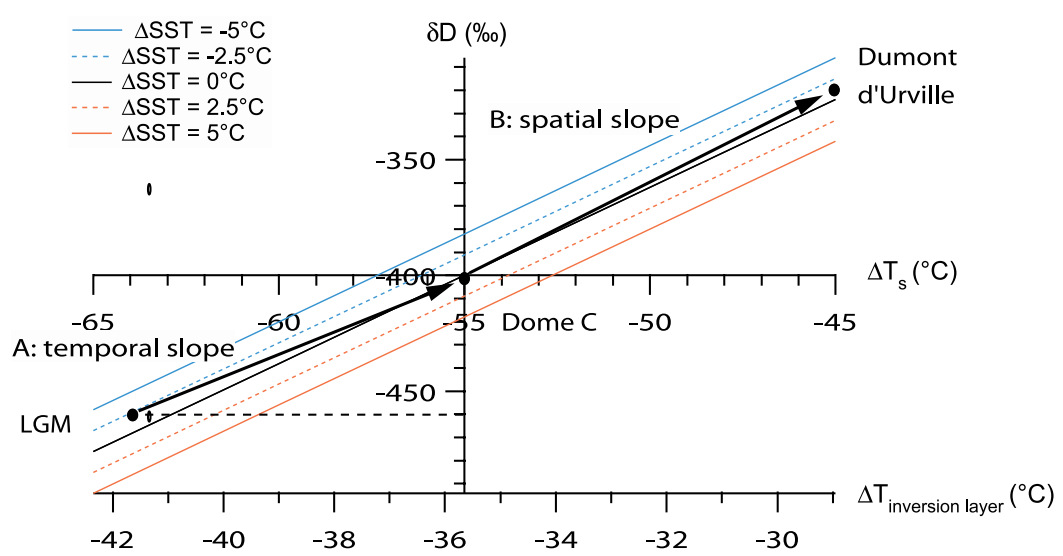

Figure 2. This figures illustrates the influence of the source temperature on the isotopic content of the Antarctic precipitation. Line B corresponds to the observed present-day spatial slope between Dumont d'Urville and Dome $\mathrm{C}$ expessed with respect to the temperature of snow formation (i.e., above the inversion layer). Line A represents the temporal slope assuming that the temperature change at the oceanic source is half that at the Dome $\mathrm{C}$ site. 


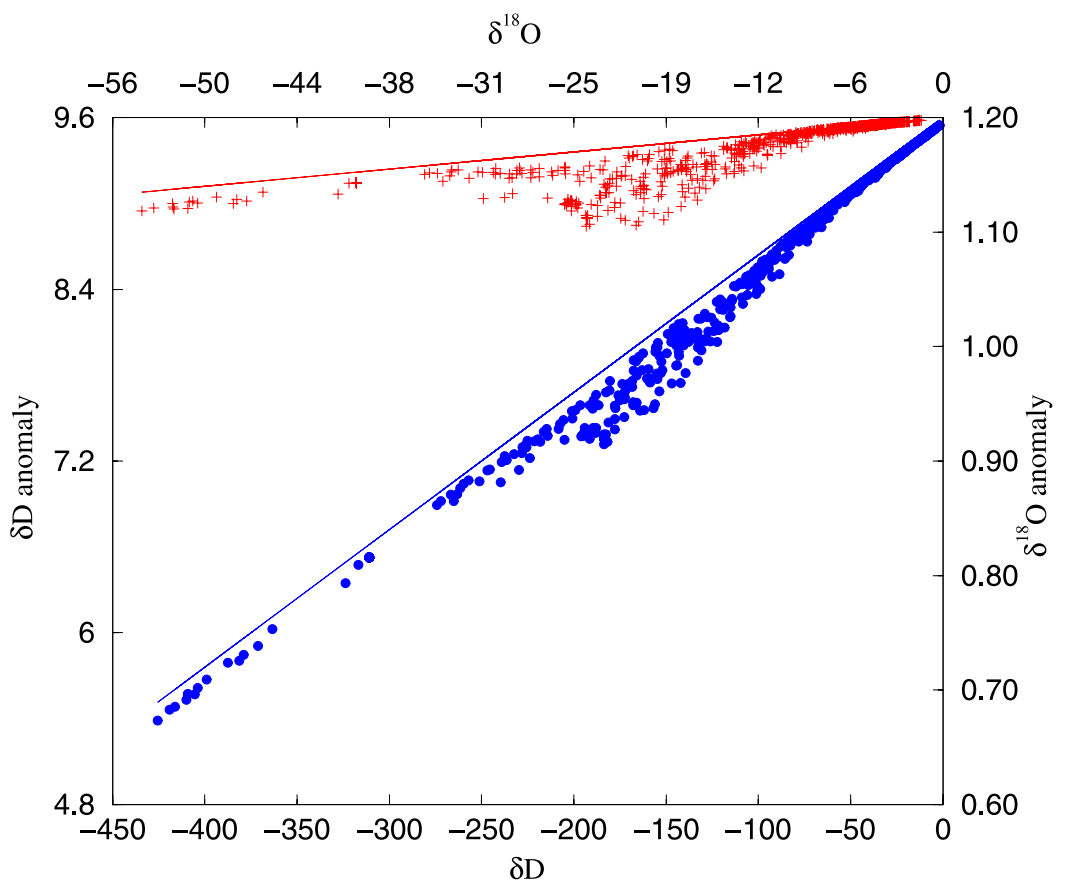

Figure 3. This plot illustrates how the oceanic correction can be estimated from a simple linear relationship directly derived from a Rayleigh type model. The points represent the oceanic correction as calculated from the difference between two GCM experiments performed by Delaygue [2000], one corresponding to the Last Glacial Maximum $\left(\delta \mathrm{D}=13.6 \% ; \delta^{18} \mathrm{O}=1.7 \%\right.$ ) and the other to modern conditions $\left(\delta \mathrm{D}=4 \% ; \delta^{18} \mathrm{O}=0.5 \%\right)$. The differences between thes two runs are calculated for each model grid point and reported as $\delta \mathrm{D}$ anomaly (in blue, left scale) and $\delta^{18} \mathrm{O}$ anomaly (in red, right scale). The two lines are directly derived from a Rayleigh type model applying the formula derived in section 3 to calculate Corr $_{\text {ocean }}$ (see text).

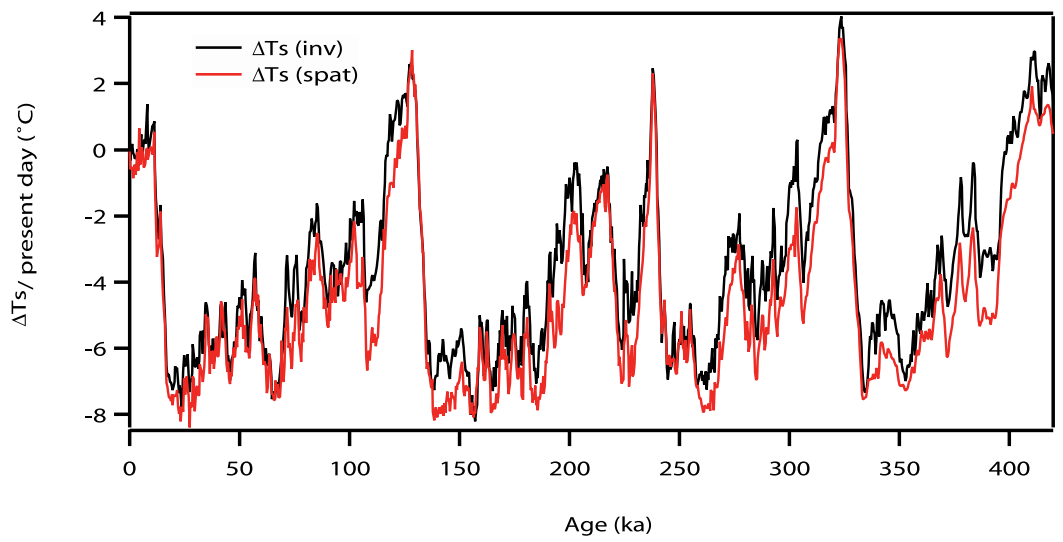

Figure 4. Vostok temperature changes from present-day values back to $420 \mathrm{kyr}$ BP, estimated either $\left(\Delta \mathrm{T}_{\mathrm{s}(\mathrm{spat})}\right.$ in red) by the conventional approach based on the $\delta \mathrm{D}$ profile alone [Petit et al., 1999] accounting correctly for the oceanic correction (see text), or $\left(\Delta \mathrm{T}_{\mathrm{s}(\mathrm{inv})}\right.$ in green) by the inverse method based on the use of deuterium-excess to account for moisture source changes [Vimeux et al., 2002]. 